\title{
Catalytic Study of the Partial Oxidation Reaction of Methanol to Formaldehyde in the Vapor Phase
}

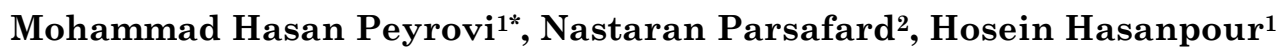 \\ ${ }^{1}$ Faculty of Chemistry and Petroleum Sciences, Department of Petroleum Chemistry and Catalysis, \\ University of Shahid Beheshti, Tehran, 1983963113, Iran \\ ${ }^{2}$ Kosar University of Bojnord, Department of Applied Chemistry, North Khorasan, 9415615458, Iran
}

Received: $1^{\text {st }}$ January 2018; Revised: $17^{\text {th }}$ July 2018 ; Accepted: $24^{\text {th }}$ July 2018 ;

Available online: 14 $4^{\text {th }}$ November 2018; Published regularly: December 2018

\begin{abstract}
In the present work, several parameters affecting on the catalytic behavior were studied in the process of partial oxidation of methanol to formaldehyde, such as: Mo/Fe ratio in unsupported catalysts, weight percent of the metallic phase in the supported catalysts, the effect of different supports, the method of Mo-Fe deposition on the supports, and the stability of the prepared catalysts against coke. These catalysts were characterized by X-ray diffraction (XRD), Fourier Transform Infra Red (FT-IR), Thermogravimetric Analysis (TGA), Scanning Electron Microscopy (SEM), $\mathrm{N}_{2}$ adsorption-desorption, and Atomic Adsorption Spectroscopy (AAS) methods. The best results (the methanol conversion $=97 \%$ and formaldehyde selectivity $=96 \%$ ) were obtained for $\mathrm{Mo}-\mathrm{Fe} / \gamma-\mathrm{Al}_{2} \mathrm{O}_{3}$ prepared by co-precipitation method with $\mathrm{Mo} / \mathrm{Fe}=1.7,50 \mathrm{wt} . \%$ of $\mathrm{Fe}-\mathrm{Mo}$ phase, $2 \mathrm{~mL} / \mathrm{h}$ methanol flow rate, and $120 \mathrm{~mL} / \mathrm{min}$ air flow rate at $350{ }^{\circ} \mathrm{C}$. Copyright (C) 2018 BCREC Group. All rights reserved
\end{abstract}

Keywords: Partial Oxidation; Methanol Conversion; Formaldehyde Selectivity; $\mathrm{Mo}-\mathrm{Fe} / \gamma-\mathrm{Al}_{2} \mathrm{O}_{3}$; co-Precipitation

How to Cite: Peyrovi, M.H., Parsafard, N., Hasanpour, H. (2018). Catalytic Study of the Partial Oxidation Reaction of Methanol to Formaldehyde in the Vapor Phase. Bulletin of Chemical Reaction Engineering \& Catalysis, 13 (3): 520-528 (doi:10.9767/bcrec.13.3.2048.520-528)

Permalink/DOI: https://doi.org/10.9767/bcrec.13.3.2048.520-528

\section{Introduction}

Achieving the highest possible performance on the oxidation reaction of methanol to formaldehyde is an essential goal of the chemical industries [1-4]. In aiming to develop catalysts with the best formaldehyde yields, good performance and catalytic stability, our efforts were focused on understanding the appropriate technique for preparation of catalysts. Ironmolybdate mixed oxides have been used in many years as a selective catalyst in the indus-

\footnotetext{
* Corresponding Author.

E-mail: m-peyrovi@sbu.ac.ir (M.H. Peyrovi)

Telp: +98-21-29902892, Fax: +98-21-22431663
}

trial production of formaldehyde from methanol oxidation with high yields [5]. The lower operating temperature and robust nature of these metal oxides have made the partial oxidation process more economically viable compared to other catalytic systems [1].

Several techniques have been reported in the preparation of unsupported iron-molybdate catalysts. Most of these methods are based on coprecipitation techniques in aqueous phase [6]. While the current iron-molybdate catalysts are unsupported catalysts, they have low surface area and weak ability to mechanical abrasion in fluidized beds. So, some researchers have been made to prepare the supported catalysts [7]. 
Although, supported catalysts have proved useful for research processes, they have been commercially unsuccessful. Because the reported supports reacted with formaldehyde leads to a lowering of the selectivity, with further oxidation to $\mathrm{CO}$ and $\mathrm{CO}_{2}$.

These reported catalysts, which are mainly prepared by impregnation method, have almost a low activity and if they have high activity, cause total oxidation, which is a doubt to the methanol-formaldehyde conversion. This is probably due to the exist of some reactions or interactions between the active phase and the support. Increase the catalytic surface is one way to increase the activity of unsupported catalysts, but we cannot change too much surface area of these catalysts and have no choice except to use supported catalysts [6].

The main purpose of the present work is to find the best $\mathrm{Mo} / \mathrm{Fe}$ ratio for the production of unsupported catalysts and finally the preparation of the supported catalysts with these ratios in order to increase the catalytic surface area without loss of activity. So, we examine the various preparation methods and compare their obtained results in oxidation reaction of methanol to formaldehyde. In the present work, the study of catalyst structure effect is also carried out on catalytic performance.

\section{Materials and Methods}

\subsection{Catalysts and Materials}

\subsubsection{Unsupported catalysts}

A series of iron-molybdate $\left(\mathrm{Fe}_{2} \mathrm{O}_{3}-\mathrm{MoO}_{3}\right)$ catalysts with different $\mathrm{Mo} / \mathrm{Fe}$ molar ratios (1.7, 2 and 3) was prepared by iron(III) nitrate nona hydrate (Merck, $\geq 98 \%$ ), ammonium hepta molybdate tetra hydrate (Merck, > $99 \%$ ), ammonia hydroxide solution (Merck, 28-30 \%) and nitric acid (Merck, $65 \%$ ) by a conventional co-precipitation method [8]. For the preparation of the catalyst, the ferric nitrate solution $(0.3 \mathrm{M})$ was added to ammonium molybdate solution $(0.1 \mathrm{M})$, under stirring at $50{ }^{\circ} \mathrm{C}$. During this process, the $\mathrm{pH}$ was adjusted between 1.5 and 2 by adding the nitric acid and ammonium hydroxide. The produced suspension was aged at $80{ }^{\circ} \mathrm{C}$ for $3 \mathrm{~h}$, cooled to room temperature and the obtained solid was filtered, dried at 100 ${ }^{\circ} \mathrm{C}$ during overnight and calcined in flowing air $\left(20 \mathrm{~mL} \cdot \mathrm{min}^{-1}\right)$ at $550{ }^{\circ} \mathrm{C}$ for $4 \mathrm{~h}$.

\subsubsection{Supported catalysts}

A modified co-precipitation method was used in the preparation of the composite catalysts. Usually various supported catalysts were manufactured by impregnation method. However, these catalysts are not active (according to our investigation) for the selective oxidation of methanol to formaldehyde. Accordingly, the modified co-precipitation method was used to prepare the composite catalysts. These composite catalysts are iron-molybdate/a-alumina, iron-molybdate/ $\gamma$-alumina and iron-molybdate/ HMS. In these catalysts, the molar ratio of $\mathrm{Mo} / \mathrm{Fe}$ is 1.7 . The $a$-alumina, $\gamma$-alumina, and HMS were prepared according to the reported procedures [9-11]. A certain amount of these supports with appropriate volume of water were poured into a beaker. The mixture was stirred to form a suspension. The $\mathrm{pH}$ of this solution was adjusted between 1.5 and 2 . To form iron-molybdate in the structure of the composite supports, a certain concentrations of metal salts solution was poured in two separate funnel and then these solutions were added drop by drop to suspension at $50{ }^{\circ} \mathrm{C}$. After adding the total solution, the reaction temperature was increased to $80^{\circ} \mathrm{C}$ for $4 \mathrm{~h}$. These solid materials were filtered, dried at $100{ }^{\circ} \mathrm{C}$ for overnight and calcined in flowing air (10 mL. $\left.\mathrm{min}^{-1}\right)$ at $400{ }^{\circ} \mathrm{C}$ for $6 \mathrm{~h}$.

The iron-molybdate catalysts with various $\mathrm{Mo} / \mathrm{Fe}$ molar ratios were named MF(x) where $x$ represents the nominal $\mathrm{Mo} / \mathrm{Fe}$ ratios (1.7, 2, and 3). The iron-molybdate/ $\gamma$-alumina catalyst with $\mathrm{Mo} / \mathrm{Fe}=1.7$ was labeled $\mathrm{MF} / \gamma-\mathrm{A}(y)$ where $y$ represents the weight percent of ironmolybdate phase in the catalyst $(30,50$, and 70 wt\%) and about iron-molybdate/a-alumina and iron-molybdate/HMS, these catalysts were named as $\mathrm{MF} / a-\mathrm{A}(y)$ and $\mathrm{MF} / \mathrm{H}(y)$, respectively $(y=50 \%)$.

\subsection{Apparatus}

Fourier transform infrared (FT-IR) spectra from 4000 to $400 \mathrm{~cm}^{-1}$ were recorded on a Bomem MB-series FT-IR (Canada) instrument model Arid-Zone TM, using KBr pellets. Powder X-ray diffraction (XRD) patterns were obtained on a Philips X'pert diffractometer with monochromatized $\mathrm{Cu}-\mathrm{K}_{\alpha}$ radiation. Thermal analysis (TG/DTA) was carried out on a Bahr STA-503 instrument in air at a heating rate of $10{ }^{\circ} \mathrm{C} . \mathrm{min}^{-1}$. The morphology of catalysts was investigated on a KYKY-EM3200 digital scanning electron microscope (KYKY SEM). The elemental compositions $(\mathrm{Mo} / \mathrm{Fe})$ were determined by an atomic absorption spectrometer (AAS AVANTA GBC). The BET surface areas of fresh catalysts were measured with a BET single point surface area (BELSORP-MR6) analyzer by $\mathrm{N}_{2}$ physisorption. 
2.3. Catalyst Testing in Reactor and Performance Calculation Methods

Methanol oxidation was performed in a continuous fixed-bed Pyrex micro reactor at an atmospheric pressure (Figure 1). Previous to starting the run, the activation of catalysts was carried out in the air flow at $400{ }^{\circ} \mathrm{C}$ for $2 \mathrm{~h}$. Then the reactant mixtures (methanol and air) were directly injected into this micro reactor by a syringe pump and mass flow controller. The catalytic performances were examined by taking $0.6 \mathrm{~g}$ of each catalyst at 250-350 ${ }^{\circ} \mathrm{C}$,

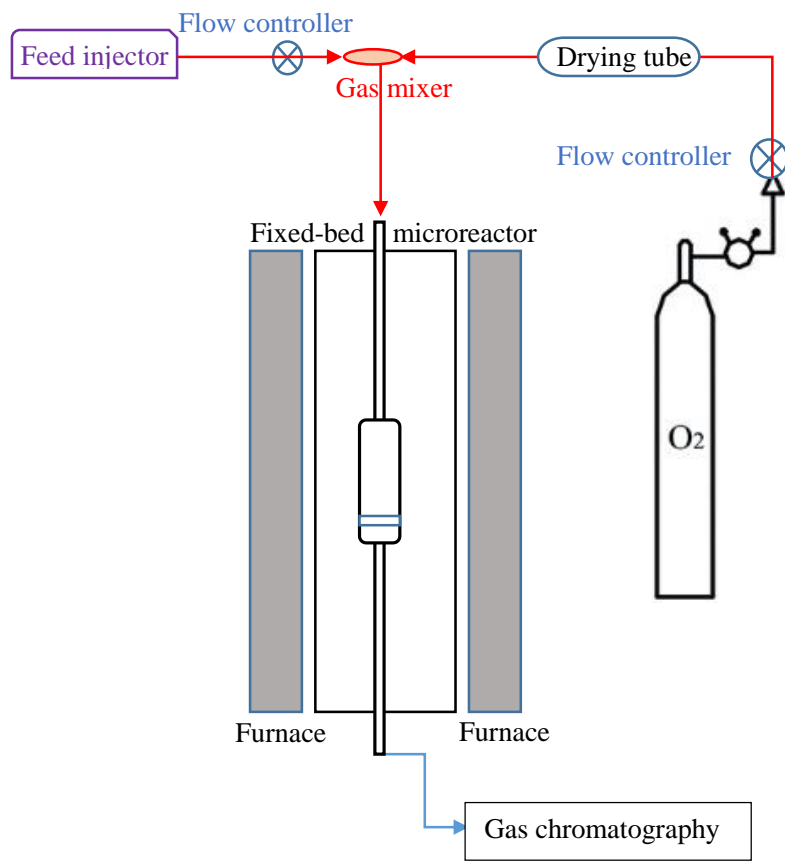

Figure 1. A schematic diagram of experimental rig setup methanol flow rate $\left(\mathrm{FR}_{\mathrm{MeOH}}\right)$ of $1-2.5 \mathrm{~mL} \cdot \mathrm{h}^{-1}$ and air flow rate $\left(\mathrm{FR}_{\text {air }}\right)$ of $20-120 \mathrm{~mL} \cdot \mathrm{min}^{-1}$ in order to study their influences for $1 \mathrm{~h}$ on stream. The stability of catalysts was also investigated during $10 \mathrm{~h}$ on stream at a selected constant temperature $\left(350{ }^{\circ} \mathrm{C}\right), \quad \mathrm{FR}_{\mathrm{MeOH}} \quad(2$ mL.h $\left.{ }^{-1}\right)$, and $\mathrm{FR}_{\text {air }}\left(120 \mathrm{~mL} \cdot \mathrm{min}^{-1}\right)$. The reaction products were analyzed online by a TCDequipped GC (Shimadzu-8A) with a Propak Q column and appropriate temperature programming for a detection of products. It is noted that all the gas lines between the micro reactor, and GC were heated to prevent condensation of products. The activity of catalysts, in terms of methanol conversion $\left(\mathrm{C}_{\mathrm{MeOH}}\right)$, the selectivity to desired products $\left(\mathrm{S}_{\mathrm{x}}\right)$, and the space velocity (SV), are defined based on the inlet and outlet mole numbers of methanol $\left(n^{i n}{ }_{\mathrm{MeOH}}\right.$ and $n^{\text {out }}{ }_{\mathrm{MeOH}}$, respectively) and product $\mathrm{x}\left(n_{x}\right)$ as follows:

$$
\begin{aligned}
& C_{\mathrm{MeOH}}(\%)=\frac{n_{\mathrm{MeOH}}^{\text {in }}-n_{\mathrm{MeOH}}^{\text {out }}}{n_{\mathrm{MeOH}}^{\text {in }}} \times 100 \\
& S_{x}(\%)=\frac{n_{x}}{n_{\mathrm{MeOH}}^{\text {in }}-n_{\mathrm{MeOH}}^{\text {out }}} \times 100 \\
& S V_{T}\left(h^{-1}\right)=\frac{\text { volumetric flow rate of the reactants }}{\text { volumeof the catalyst in reactor }}
\end{aligned}
$$

\section{Results and Discussion}

Table 1 summarizes the results of catalytic performance of the unsupported catalysts for methanol partial oxidation at different temperatures and space velocities. Under our ex-

\begin{tabular}{|c|c|c|c|c|c|c|c|c|c|c|}
\hline & \multirow{2}{*}{ Catal. } & \multicolumn{5}{|c|}{$T\left({ }^{\circ} \mathrm{C}\right)^{*}$} & \multicolumn{4}{|c|}{$S V_{350}\left(\mathrm{~h}^{-1}\right)^{* *}$} \\
\hline & & 250 & 270 & 300 & 330 & 350 & 7422 & 12580 & 20106 & 35158 \\
\hline \multirow{3}{*}{$C_{\mathrm{MeOH}}(\%)$} & $\mathrm{MF}(1.7)$ & 38 & 43 & 51 & 64 & 81 & 50 & 64 & 81 & 88 \\
\hline & $\mathrm{MF}(2.0)$ & 27 & 35 & 40 & 52 & 60 & 49 & 57 & 60 & 70 \\
\hline & $\mathrm{MF}(3.0)$ & 23 & 30 & 35 & 37 & 40 & 33 & 34 & 40 & 47 \\
\hline \multirow{3}{*}{$S_{H C H O}(\%)$} & $\mathrm{MF}(1.7)$ & 98 & 88 & 87 & 75 & 56 & 78 & 73 & 56 & 74 \\
\hline & $\operatorname{MF}(2.0)$ & 100 & 100 & 91 & 88 & 73 & 82 & 80 & 73 & 85 \\
\hline & $\mathrm{MF}(3.0)$ & 100 & 100 & 100 & 96 & 80 & 95 & 94 & 88 & 90 \\
\hline \multirow{3}{*}{$S_{D M E}(\%)$} & $\mathrm{MF}(1.7)$ & 10 & 12 & 13 & 25 & 44 & 22 & 27 & 44 & 26 \\
\hline & $\mathrm{MF}(2.0)$ & 0 & 0 & 9 & 12 & 27 & 18 & 20 & 27 & 15 \\
\hline & $\operatorname{MF}(3.0)$ & 0 & 0 & 0 & 4 & 20 & 5 & 6 & 12 & 10 \\
\hline
\end{tabular}

Table 1. The effect of temperature and space velocity on $\mathrm{C}_{\mathrm{MeOH}}$, $\mathrm{S}_{\mathrm{HCHO}}$, and $\mathrm{S}_{\mathrm{DmE}}$ for unsupported catalysts

*Experimental conditions: $\mathrm{FR}_{\text {air }}=60 \mathrm{~mL} \cdot \mathrm{min}^{-1}$ and $\mathrm{FR}_{\mathrm{MeOH}}=2 \mathrm{~mL} \cdot \mathrm{h}^{-1}$.

** Experimental conditions: $\mathrm{T}=350{ }^{\circ} \mathrm{C}, \mathrm{FR}$ air $=20-120 \mathrm{~mL} \cdot \mathrm{min}^{-1}$ and $\mathrm{FR}_{\mathrm{MeOH}}=2 \mathrm{~mL} \cdot \mathrm{h}^{-1}$. 
perimental conditions, the only detectable products in this reaction were formaldehyde (HCHO), dimethyl ether (DME), and small amounts of $\mathrm{CO}_{2}$. The results show a similar trend for all three catalysts with temperature. As the temperature increases, the methanol conversion $\left(C_{\mathrm{MeOH}}\right)$ increases and the selectivity to formaldehyde $\left(\mathrm{S}_{\mathrm{HCHO}}\right)$ decreases. At higher temperatures, the catalysts tend to produce more DME. Among the prepared catalysts, $\mathrm{MF}(1.7)$ catalyst has the best methanol conversion. However, its selectivity to formaldehyde is lower than the other unsupported catalysts. The yields of these catalysts confirm the superiority of $\mathrm{MF}(1.7)$ compared to others.

The results show that with promoting the Mo and Fe amounts, the $S_{\mathrm{HCHO}}$ and $C_{\mathrm{MeOH}}$ increases. In the study about the SV effect, the results (Table 1) show that with increasing SV, the $C_{\mathrm{MeOH}}$ raises linearly, probably due to the increase as the concentration of $\mathrm{O}_{2}$ in the reaction environment. In all three catalysts, the selectivity to the products increases with space velocity from a maximum to a minimum value. It increases again and reaches to the highest possible amount at the maximum SV. The most probable reason for this observation is the low contact time at the maximum SV, followed by the increase of selectivity to desired products and the decrease of unwanted products. The $C_{\text {МеӦ }}$ for the $\mathrm{MF}(1.7)$ catalyst at the $\mathrm{SV}=$ $37,000 \mathrm{~h}^{-1}$ is nearly $90 \%$. After this SV, the catalyst activity has a decreasing trend.
Due to the use of unsupported catalysts in the industry, less research has been done on the study of supported catalysts. Accordingly, in the present work, three catalysts containing 10, 20, and 30 wt.\% of Fe-Mo on $\gamma$-alumina with $\mathrm{Mo} / \mathrm{Fe}$ ratio of 1.7 were obtained by impregnation method. Although these catalysts had a high conversion, their major product was carbon oxides $\left(\mathrm{CO}_{\mathrm{x}}\right)$. So these catalysts tend to total oxidation reaction. The Mo-Fe supported ZSM-5 and HMS catalysts were also prepared by this method. These catalysts were furthermore shown the same results but with lower products. To reduce total oxidation reaction, we changed the catalyst preparation method from impregnation to co-precipitation method. Since the best performance of unsupported catalysts was at two temperatures (300 and $350{ }^{\circ} \mathrm{C}$ ), these temperatures was selected in order to study of supported catalysts.

To investigate the best weight percent of metallic phase, three amounts $(30,50$, and 70 wt.\%) of Fe-Mo phase were also investigated. The results were summarized in Table 2 . The obtained results present that the $\mathrm{MF} / \gamma-\mathrm{A}(50)$ catalyst has high $S_{\mathrm{HCHO}}$. This catalyst has the best performance at $350{ }^{\circ} \mathrm{C}$ and $37,000 \mathrm{~h}^{-1}$ and produces $\mathrm{HCHO}$ at a yield of more than $97 \%$. In other words, this catalyst has a strong tendency to produce $\mathrm{HCHO}$, the lack of $\mathrm{CO}_{\mathrm{x}}$ and high $C_{\text {меон. }}$. The results show that $S_{\text {Нсно }}$ increases with promoting SV. The MF/ $\gamma-\mathrm{A}(30)$ catalyst has a behavior similar to the $\mathrm{MF}(1.7)$ catalyst at $350{ }^{\circ} \mathrm{C}$. This catalyst produces some

Table 2. The effect of space velocity at 300 and $350{ }^{\circ} \mathrm{C}$ on $\mathrm{C}_{\mathrm{MeOH}}, \mathrm{S}_{\mathrm{HCHO}}$, and $\mathrm{S}_{\mathrm{DME}}$ for supported catalysts

\begin{tabular}{|c|c|c|c|c|c|c|c|c|c|}
\hline & \multirow{2}{*}{ Catalysts } & \multicolumn{4}{|c|}{$\mathrm{SV}_{300}\left(\mathrm{~h}^{-1}\right)^{*}$} & \multicolumn{4}{|c|}{$\mathrm{SV}_{350}\left(\mathrm{~h}^{-1}\right)^{*}$} \\
\hline & & 6956 & 11570 & 18692 & 32336 & 6956 & 11570 & 18692 & 32336 \\
\hline \multirow{3}{*}{$\mathrm{C}_{\mathrm{MeOH}}(\%)$} & $\mathrm{MF} / \gamma-\mathrm{A}(30)$ & 41 & 54 & 56 & 70 & 52 & 63 & 82 & 98 \\
\hline & $\mathrm{MF} / \gamma-\mathrm{A}(50)$ & 30 & 34 & 40 & 67 & 54 & 51 & 86 & 97 \\
\hline & $\mathrm{MF} / \gamma-\mathrm{A}(70)$ & 20 & 35 & 57 & 86 & 32 & 62 & 97 & 99 \\
\hline \multirow{3}{*}{$\mathrm{S}_{\text {нсно }}(\%)$} & $\mathrm{MF} / \gamma-\mathrm{A}(30)$ & 79 & 63 & 72 & 69 & 68 & 73 & 75 & 61 \\
\hline & $\mathrm{MF} / \gamma-\mathrm{A}(50)$ & 82 & 86 & 93 & 90 & 83 & 89 & 85 & 96 \\
\hline & $\mathrm{MF} / \gamma-\mathrm{A}(70)$ & 100 & 84 & 79 & 85 & 96 & 84 & 83 & 77 \\
\hline \multirow{3}{*}{$\mathrm{S}_{\mathrm{DME}}(\%)$} & $\mathrm{MF} / x-\mathrm{A}(30)$ & 21 & 37 & 21 & 26 & 30 & 17 & 12 & 10 \\
\hline & $\mathrm{MF} / \gamma-\mathrm{A}(50)$ & 12 & 14 & 7 & 10 & 17 & 11 & 15 & 4 \\
\hline & $\mathrm{MF} / \gamma-\mathrm{A}(70)$ & 0 & 16 & 21 & 15 & 4 & 16 & 17 & 23 \\
\hline $\mathrm{S}_{\mathrm{COx}}(\%)$ & $\mathrm{MF} / \gamma-\mathrm{A}(30)$ & 0 & 0 & 7 & 5 & 2 & 10 & 13 & 29 \\
\hline
\end{tabular}

*Experimental conditions: $\mathrm{FR}_{\text {air }}=20-120 \mathrm{~mL} \cdot \mathrm{min}^{-1}$ and $\mathrm{FR}_{\mathrm{MeOH}}=2 \mathrm{~mL} \cdot \mathrm{h}^{-1}$ 
$\mathrm{CO}_{\mathrm{x}}$ during the reaction. The $80 \%$ of $\mathrm{C}_{\mathrm{MeOH}}$ and $70 \%$ of $S_{\mathrm{HCHO}}$ are the best results for this catalyst. The $\mathrm{MF} / \gamma-\mathrm{A}(70)$ catalyst does not generate $\mathrm{CO}_{\mathrm{x}}$ and it is not effective in the production of $\mathrm{HCHO}$ as much as $\mathrm{MF} / \gamma-\mathrm{A}(50)$ catalyst. Its $S_{H C H O}$ decreases with increasing SV. Furthermore, with increasing $\mathrm{O}_{2}$ concentration, the $C_{\mathrm{MeOH}}$ reaches to a maximum value and then remains constant. In the low conversions, the reaction yield to $\mathrm{HCHO}$ is close to $100 \%$.

According to the above results, a catalyst containing 50 wt.\% of Fe-Mo over $\gamma$-alumina has the best results. In order to compare the different supports, the $a$-alumina and HMS were also co-precipitated with 50 wt.\% of Fe-Mo. As can be seen in Figure 2, the $\mathrm{MF} / a-\mathrm{A}(50)$ catalyst has less activity than the other three catalysts. The MF/HMS(50) catalyst has high activity for this reaction, like the

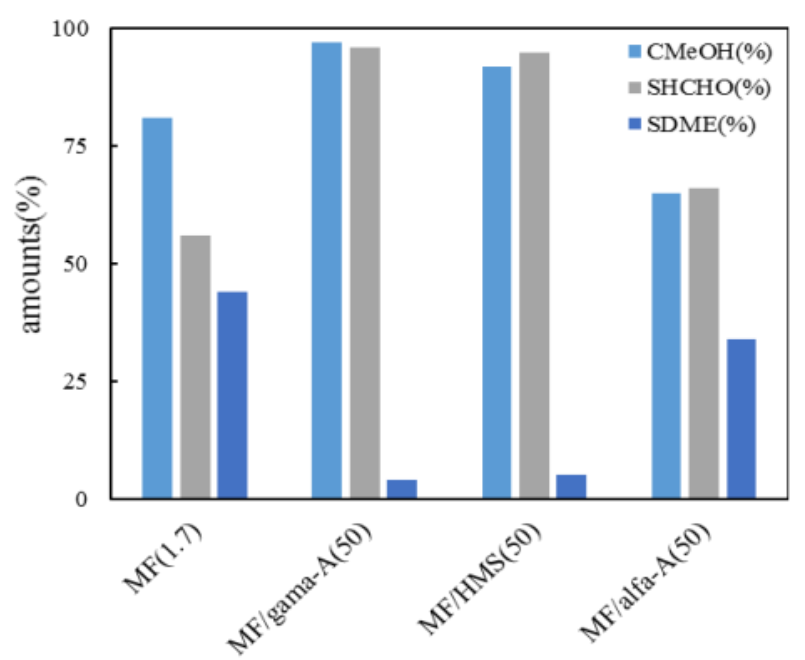

Figure 2. Comparison of the catalytic performance for different supported catalysts prepared by co-precipitation method

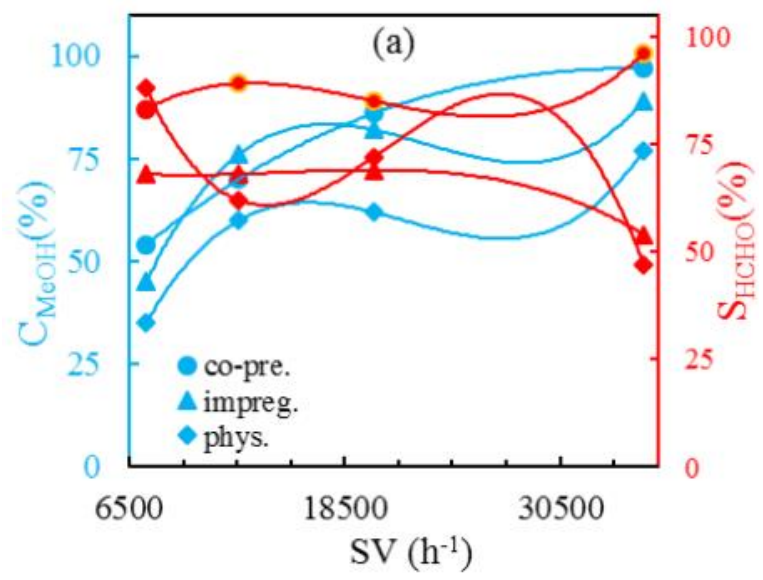

$\mathrm{MF} / \gamma-\mathrm{A}(50)$. It seems that the surface area of these catalysts is effective on these results.

To investigate the effect of catalyst preparation method on the catalytic performance, $\mathrm{MF} / \gamma-\mathrm{A}(50)$ was prepared by impregnation (impreg.), co-precipitation (co-pre.) and physical mixing (phys.) methods. In the catalyst produced by the impregnation and physical mixing methods, the $S_{\mathrm{CO} 2}$ and $S_{\mathrm{CO}}$ as byproducts are high, while in the catalyst prepared by coprecipitation, almost no $\mathrm{CO}_{2}$ is produced (Figure 3). The impregnated catalyst tends to total oxidation and nearly $40 \%$ of its products is $\mathrm{CO}$ and $\mathrm{CO}_{2}$. With increasing $\mathrm{SV}$, the total oxidation is also exacerbated. In the physical mixed catalyst, the complete oxidation process reaches to a minimum with increasing $\mathrm{SV}$. From these results, it is determined that the best method to the preparation of the catalysts is the co-precipitation method. The catalysts produced by this method, in addition to the great $C_{\mathrm{MeOH}}$, also have a high selectivity to the desired product, and by-products are minimized.

Another parameter that was considered in the performance of the best catalysts described above is the effect of $\mathrm{FR}_{\mathrm{MeOH}}$ (Figure $4 \mathrm{a}$ ). This investigation was carried out at $\mathrm{FR}_{\text {air }}$ of 120 $\mathrm{mL} / \mathrm{min}$ and $350{ }^{\circ} \mathrm{C}$. As shown for $\mathrm{MF}(1.7)$, in $\mathrm{FR}_{\mathrm{MeOH}}$ of $1 \mathrm{~mL} / \mathrm{h}$, the $C_{\mathrm{MeOH}}$, and $S_{\mathrm{HCHO}}$ are almost $100 \%$ and $80 \%$, respectively. With increasing $\mathrm{FR}_{\mathrm{MeOH}}$ and reaching to $2.5 \mathrm{~mL} / \mathrm{h}$, both parameters attain nearly $70 \%$. This result is probably because in less $\mathrm{FR}_{\mathrm{MeOH}}$, there is enough $\mathrm{O}_{2}$ to perform the oxidation reaction. Even so, as the $\mathrm{O}_{2}$ ratio drops in high $\mathrm{FR}_{\mathrm{MeOH}}$, a dewatering reaction occurs. For $\mathrm{MF} / \gamma-\mathrm{A}(50)$, in $\mathrm{FR}_{\mathrm{MeOH}}$ of $1 \mathrm{~mL} / \mathrm{h}, \mathrm{C}_{\mathrm{MeOH}}$ is close to $100 \%$ and $S_{\mathrm{HCHO}}$ is near $85 \%$. By increasing $\mathrm{FR}_{\mathrm{MeOH}}$ to $2 \mathrm{~mL} / \mathrm{h}$, both parameters reach $97 \%$, and

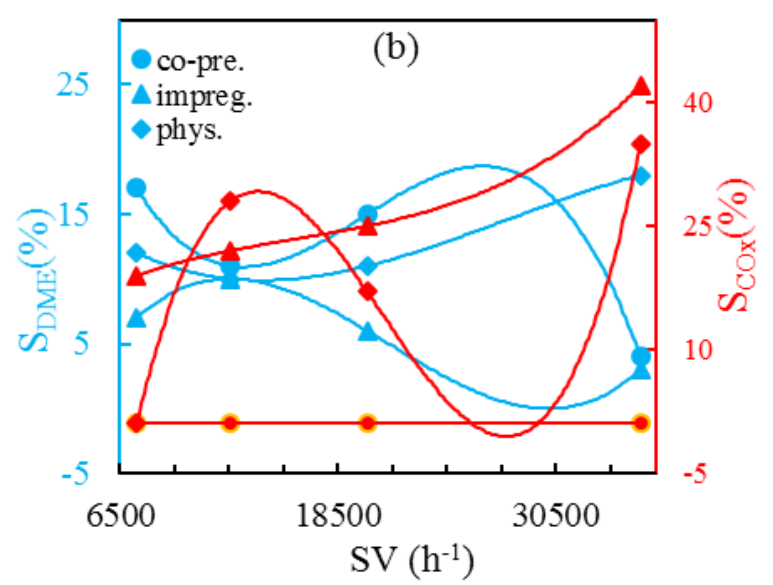

Figure 3. Effect of preparation method on (a) conversion and selectivity to the desired product and (b) selectivity to by-products 
again a decreasing trend can be observed. The MF/HMS(50) catalyst tends to total oxidation, and the best performance of this catalyst is achieved at $\mathrm{FR}_{\mathrm{MeOH}}$ of $2 \mathrm{~mL} / \mathrm{h}$, and then the catalyst performance reduces once again.

To better study, the catalytic stability against deactivation agents (coke deposition) was investigated over $10 \mathrm{~h}$ on stream (Figure $4 \mathrm{~b})$. The stability test was carried out in $\mathrm{FR}_{\text {air }}$ of $120 \mathrm{~mL} / \mathrm{min}, \mathrm{FR}_{\mathrm{MeOH}}$ of $2 \mathrm{~mL} / \mathrm{h}$ and $350{ }^{\circ} \mathrm{C}$. After $10 \mathrm{~h}, \mathrm{C}_{\mathrm{MeOH}}$ of $\mathrm{MF}(1.7)$ decreases about 30 $\%$. While $S_{\mathrm{HCHO}}$ is not only diminished over time but also has a relative increase. For $\mathrm{MF} / \gamma$-A(50), $S_{\text {HСНо }}$ decreases significantly after $1 \mathrm{~h}$, reaches a minimum and increases again. $C_{\mathrm{MeOH}}$ has also a decreasing trend and reaches $80 \%$ after $10 \mathrm{~h}$. While $S_{D M E}$ increases over time. For MF/HMS(50), after $10 \mathrm{~h}, C_{\mathrm{MeOH}}$ downfalls from 90 to $70 \%$. SHCHO reaches to a minimum value over time, and it goes up again. This catalyst also shows the worst possible performance at 8th hour.

The amount of coke depositions after $10 \mathrm{~h}$ was evaluated by thermal gravimetric analysis (TGA). The lowest amount of coke has been deposited on $\mathrm{MF}(1.7)$ catalyst (0.008 wt.\%), and this amount confirms the high activity of this catalyst after $10 \mathrm{~h}$. The coke amounts of $\mathrm{MF} / \gamma-\mathrm{A}(50)$ and $\mathrm{MF} / \mathrm{HMS}(50)$ are 0.022 and 0.034 wt.\%, respectively. As expected, because of the presence of $\mathrm{O}_{2}$, suitable conditions for burning coke and the presence of a clean hydrocarbon, the coke formation over these catalysts is very low.

To investigate the relationship between the obtained results and the structural properties of these catalysts, various analyzes were performed as follows. The Mo and Fe contents in the prepared catalysts were analyzed with atomic absorption spectroscopy. The obtained

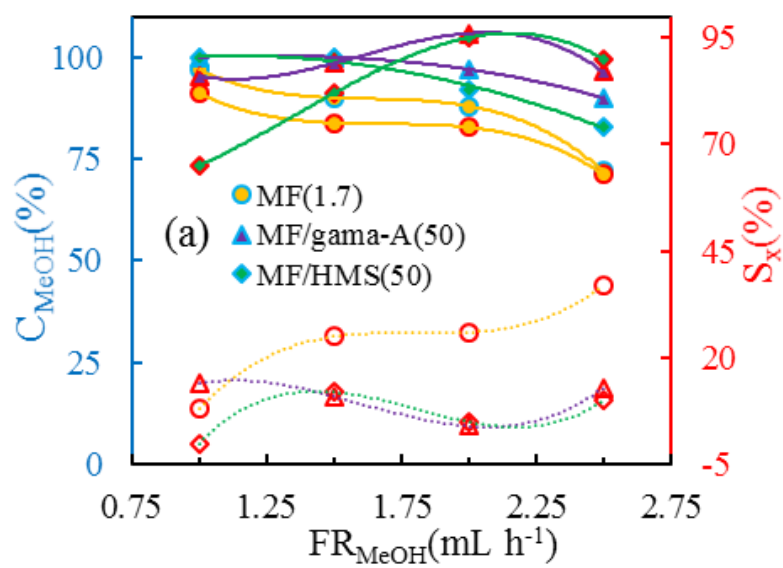

results show a deviation of less than \pm 0.1 from the desired values. The BET surface area $\left(S_{B E T}\right)$ for the fresh catalysts was measured by $\mathrm{N}_{2}$ adsorption-desorption. The results briefly for unsupported $\mathrm{MF}(1.7), \mathrm{MF}(2)$ and $\mathrm{MF}(3)$ catalysts are $3.1,3.5$ and $5.2 \mathrm{~m}^{2} / \mathrm{g}$ and also for supported $\mathrm{MF} / \gamma-\mathrm{A}(50), \mathrm{MF} / \mathrm{a}-\mathrm{A}(50)$ and $\mathrm{MF} / \mathrm{HMS}(50)$ catalysts are $146.2,6.7$, and $811.9 \mathrm{~m}^{2} / \mathrm{g}$, respectively. As expected the unsupported catalysts have the lowest surface area than the supported catalysts. Also, the catalysts prepared with coprecipitation method presented the lowest surface area than the catalysts prepared with impregnation and physical mixing methods.

Figure 5 shows the XRD patterns of the selected catalysts. In these patterns, three main phases can be identified as $\mathrm{Fe}_{2}\left(\mathrm{MoO}_{4}\right)_{3}, \mathrm{MoO}_{3}$, and $\mathrm{Fe}_{2} \mathrm{O}_{3}$ (Table 3). The peaks at $19.5^{\circ}, 20.5^{\circ}$, $21.8^{\circ}, 23^{\circ}$, and $31^{\circ}$ indicate (040), (313), (214), (202) and (143) planes for the $\mathrm{Fe}_{2}\left(\mathrm{MoO}_{4}\right)_{3}$ phase, respectively. The most important peak

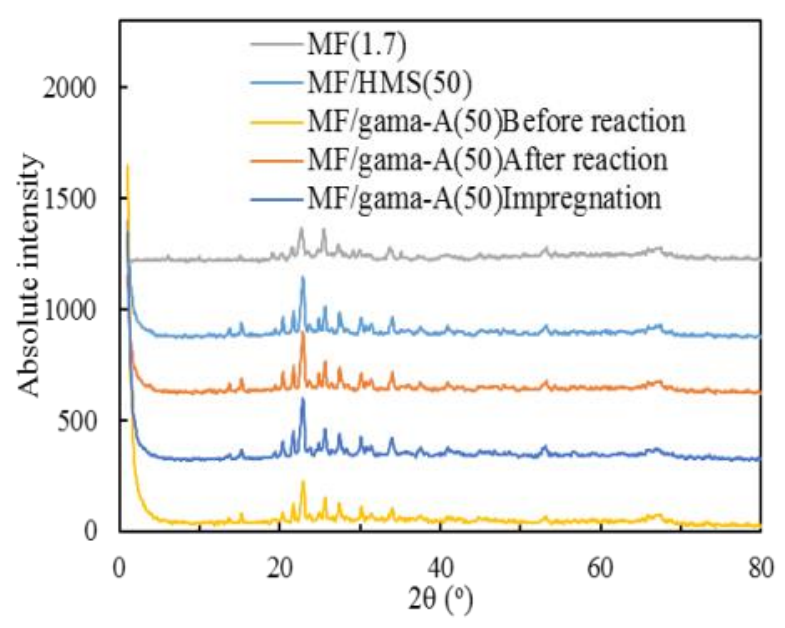

Figure 5. Comparative X-ray diffraction patterns for the prepared catalysts

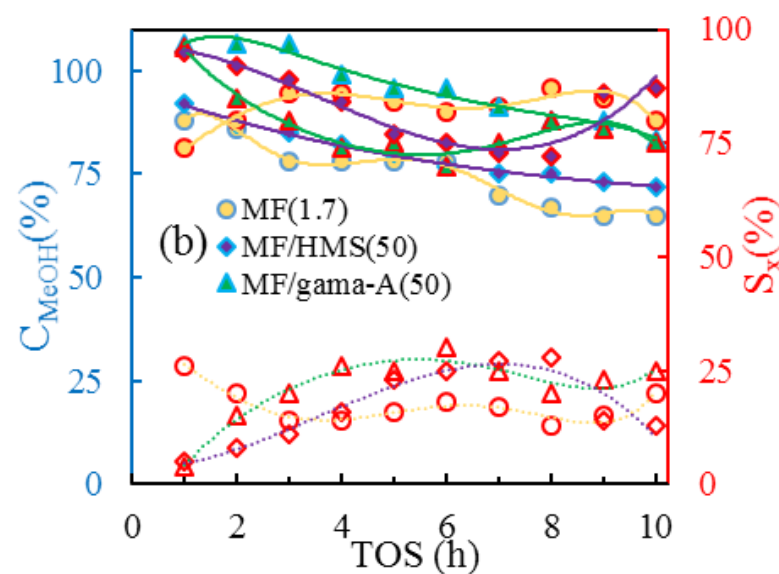

Figure 4. $C_{\mathrm{MeOH}}$ and $S_{x}$ against (a) $\mathrm{FR}_{\mathrm{MeOH}}$ and (b) TOS. (Markers with blue border: $C_{\mathrm{MeOH}}$; Markers with red border and solid lines: $S_{H C H O}$ and dash lines: $\left.S_{M D E}\right)$ 
$\left(23^{\circ}\right)$ is observed in all catalysts with different intensity. The peaks at $12.8^{\circ}, 25.7^{\circ}, 27.3^{\circ}$, and $39.2^{\circ}$ can be indexed to correspond with the (020), (040), (021), and (060) planes of $\mathrm{MoO}_{3}$ phase. The intensity of molybdenum oxide peaks relative to the iron oxide is more intense due to the crystallization in a more regular crystalline network. Also, the peaks at $24.16^{\circ}$, $33.2^{\circ}, 35.66^{\circ}, 40.9^{\circ}, 49.57^{\circ}, 54.12^{\circ}, 61.74^{\circ}$, and $64.62^{\circ}$ indicate the presence of iron phases in the catalysts [1].

To investigate the effect of reaction time on the catalysts structure, $\mathrm{MF} / \gamma-\mathrm{A}(50)$ catalyst was examined before and after $30 \mathrm{~h}$ of reaction by XRD analysis (Figure 5). The XRD patterns of these catalysts do not differ from each other, and this shows the thermal and mechanical stability of this catalyst. Although the catalyst activity is reduced over time that the point for this can be seen in the difference of the peaks' width before and after the reaction. The data in Table 3 show after the reaction, the peak width of $\mathrm{Fe}_{2}\left(\mathrm{MoO}_{4}\right)_{3}$ increases and the particle size reaches from 29 to $18 \mathrm{~nm}$. But $\mathrm{Fe}_{2} \mathrm{O}_{3}$ and $\mathrm{MoO}_{3}$ phases do not change. Increasing the peak width means the distribution of the crystal structure and so the reduction of the particle size. As a result, these data indicate that the cause of catalyst deactivation after the reaction is the loss of the $\mathrm{Fe}_{2}(\mathrm{MoO})_{3}$ phase. About the effect of the preparation method on the structure of the catalysts, it can be said that the intensity and width of the peaks are different, indicating a difference in particle size and crystallinity. These two factors are affecting on the activity of these two catalysts.

The peak width of $\mathrm{Fe}_{2}\left(\mathrm{MoO}_{4}\right)_{3}$ phase for impregnated catalysts is more than the catalysts prepared by co-precipitation method. According to the Scherrer equation, the greater peak width represents the smaller particle size.
Therefore, the larger particle size of the active phase in the co-precipitation method is in favor of this catalytic oxidation. These results are in accordance to the obtained particle size from SEM.

SEM images (Figure 6) show the difference in crystalline order for various prepared catalysts. According to the activity results, the unsupported catalysts and the catalysts prepared by the co-precipitation method have high activity, which the SEM images show more crystalline order for these catalysts. The $\mathrm{MF}(1.7)$ and $\mathrm{MF} / \gamma$-A(50) catalysts have three-dimensional order, while the MF/HMS(50) catalyst has sheet structure and two-dimensional order. The image of the $\mathrm{MF} / \gamma-\mathrm{A}(50)$ catalyst prepared by co-precipitation method is very similar to $\mathrm{MF}(1.7)$ prepared by this method.

Figure 7a shows the FT-IR spectra for unsupported catalysts. The broad band available in $835 \mathrm{~cm}^{-1}$ shows the stretching vibration of the $\mathrm{Mo}=\mathrm{O}$ in the $\mathrm{Fe}_{2}\left(\mathrm{MoO}_{4}\right)_{3}$ active phase. There are also two shoulders in 958 and 1000 $\mathrm{cm}^{-1}$, which are related to the bond between $\mathrm{O}$ and $\mathrm{Mo}$ in a separate phase of $\mathrm{MoO}_{3}$. The small spectrum available in the $470 \mathrm{~cm}^{-1}$ indicates a bending vibration of the Mo-O-Mo, which its intensity decreases with increasing Fe content. As it is not visible in the catalyst with $\mathrm{Mo} / \mathrm{Fe}$ equal to 1.7 . The relatively broad peak at 600 $\mathrm{cm}^{-1}$ can be related to the Mo in the hexagonal structure of $\mathrm{MoO}_{6}$. However, this peak is located in the stretching frequency range of the $\mathrm{Fe}-\mathrm{O}$ bond and overlaps it. The vibration bands related to $\mathrm{Fe}$ are present in low frequency ranges, which may also be covered by the vibration bands of Mo bonds.

The IR spectrum of $\mathrm{MF}(1.7)$ catalyst is very similar to the $\mathrm{MF}(3)$ spectrum, but there are two minor differences that are used to identify the Fe bands. These differences include the

Table 3. The structural properties of prepared catalysts from XRD and SEM analysis

\begin{tabular}{lccccc}
\hline \multicolumn{4}{c}{ peak width of metallic phases } & \multicolumn{2}{c}{} \\
\cline { 2 - 5 } & $\mathrm{Fe}_{2}\left(\mathrm{MoO}_{4}\right)_{3}$ & $\mathrm{MoO}_{3}$ & $\mathrm{Fe}_{2} \mathrm{O}_{3}$ & \\
\hline Catalyst & $2 \theta=22.88^{\circ}$ & $2 \theta=25.49^{\circ}$ & $2 \theta=33.74^{\circ}$ & $\mathrm{P}_{\mathrm{s}}(\mathrm{nm})^{1}$ & $\mathrm{P}_{\mathrm{s}}(\mathrm{nm})^{2}$ \\
\hline $\mathrm{MF}(1.7)$ & 0.47 & 0.24 & 0.35 & 22 & 33 \\
$\mathrm{MF} / \mathrm{HMS}(50)$ & 0.24 & 0.18 & 0.24 & 36 & 42 \\
$\mathrm{MF} / \gamma-\mathrm{A}(50)^{3}$ & 0.29 & 0.24 & 0.24 & 29 & 40 \\
$\mathrm{MF} / \gamma-\mathrm{A}(50)^{4}$ & 0.53 & 0.24 & 0.47 & 16 & 20 \\
$\mathrm{MF} / \gamma-\mathrm{A}(50)^{5}$ & 0.47 & 0.24 & 0.24 & 18 & - \\
\hline
\end{tabular}

${ }^{1}$ particles size calculated by Scherrer equation; ${ }^{2}$ particles size calculated by SEM; ${ }^{3}$ catalyst prepared by coprecipitation method; ${ }^{4}$ catalyst prepared by impregnation method; ${ }^{5}$ catalyst prepared by co-precipitation method after $30 \mathrm{~h}$ on stream 
presence of a truly broad band in $3300 \mathrm{~cm}^{-1}$, which indicates the stretching vibration of the $\mathrm{FeOOH}$ hydroxyl group, and the existence of a very small peak at $1630 \mathrm{~cm}^{-1}$, which is difficult to observe in more molybdenum-containing catalysts. This peak relates to the bending vibration of the $\mathrm{FeOOH}$ hydroxyl group. By comparing the FT-IR spectra of these three catalysts, it is observed that with increasing Mo content, the peak intensity in the $1630 \mathrm{~cm}^{-1}$ re- gion reduces and the intensity of Mo peaks increases [6].

Figure $7 \mathrm{~b}$ shows the effects of supports and the preparation method on the FT-IR spectra. The FT-IR spectra of $\mathrm{MF} / \gamma-\mathrm{A}(\mathrm{y})$ catalysts produced by co-precipitation method show a broad band in 3500 and $840 \mathrm{~cm}^{-1}$ that are related to the stretching vibration of the surface hydroxyl groups $(\mathrm{O}-\mathrm{H})$ and the molybdenum-oxygen bonds (Mo-O), respectively. It seems that the
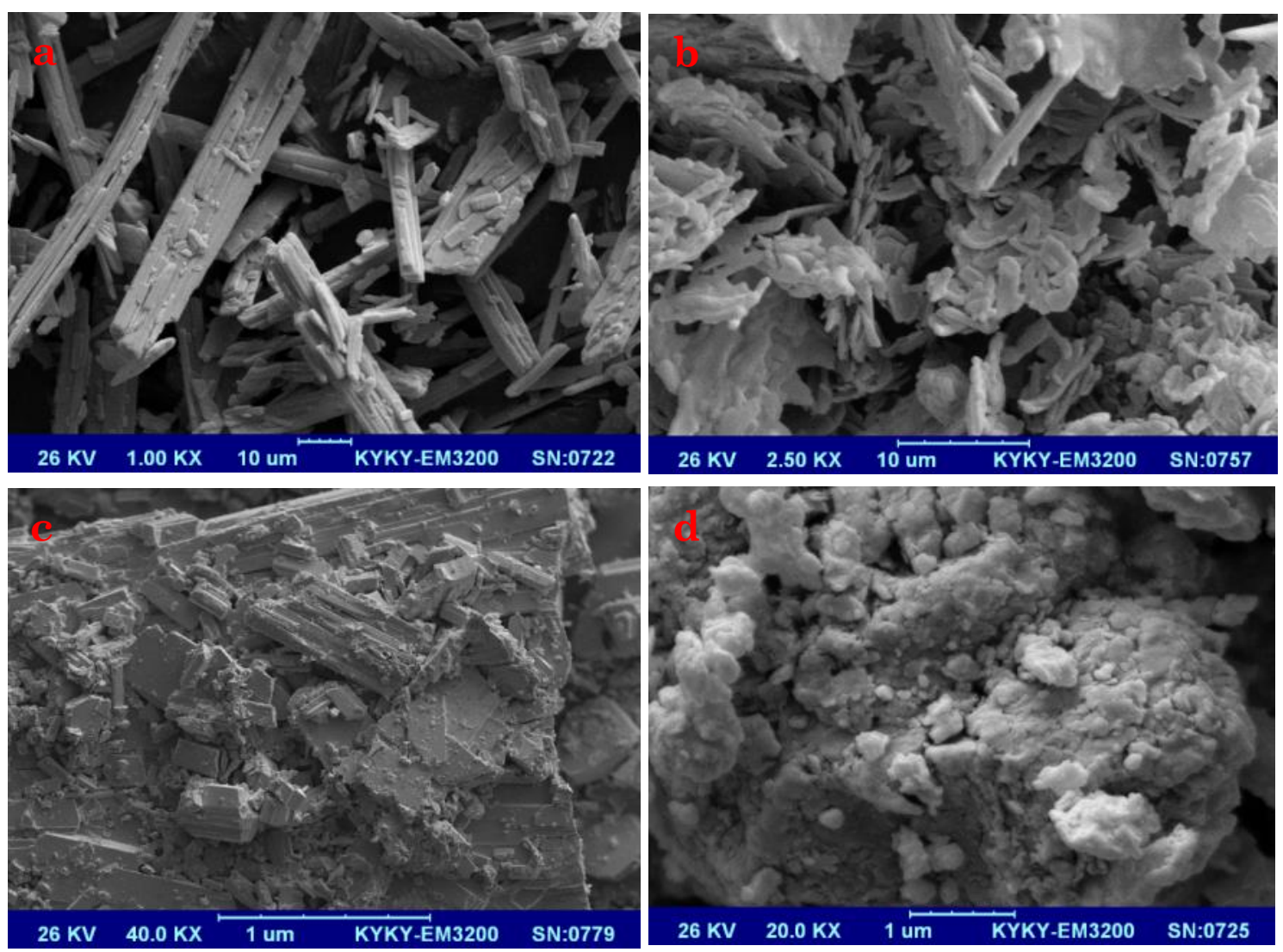

Figure 6. SEM images for (a) $\mathrm{MF}(1.7)$, (b) $\mathrm{MF} / \mathrm{HMS}(50)$, (c) $\mathrm{MF} / \gamma-\mathrm{A}(50)$ prepared by co-precipitation method and (d) $\mathrm{MF} / \gamma-\mathrm{A}(50)$ prepared by impregnation method
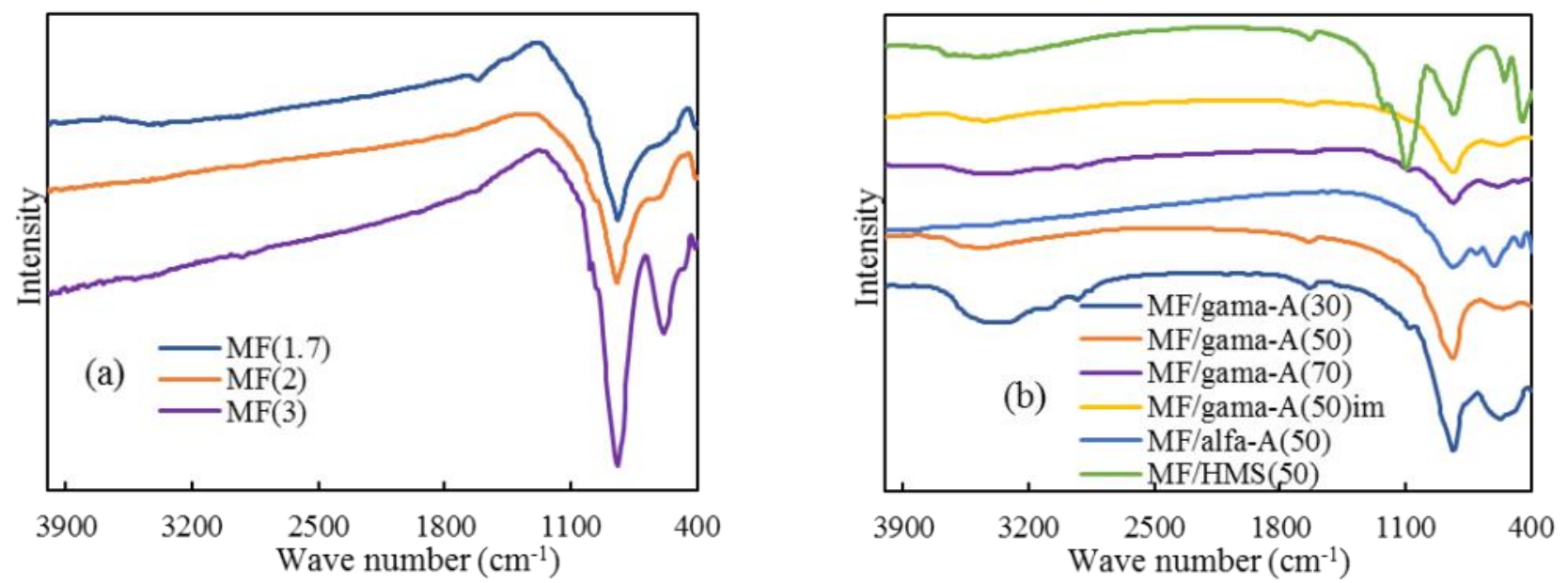

Figure 7. IR spectra for (a) unsupported and (b) supported catalysts 
Fe vibration bands are covered by the $\gamma$-alumina bands. The FT-IR spectra of $\mathrm{MF} / \gamma-\mathrm{A}(50 \%)$ catalysts, which have been prepared by two methods of co-precipitation and impregnation, show that the change in the preparation method has almost no effect on the FT-IR spectra of these catalysts. This result was also confirmed by XRD patterns. The MF/HMS (50 \%) prepared by co-precipitation method presents the asymmetric stretching vibration of the $\mathrm{Si}-\mathrm{O}-\mathrm{Si}$ group in 1024 and 1200 $\mathrm{cm}^{-1}$ and the symmetric stretching vibration in $812 \mathrm{~cm}^{-1}$. The observed band in $950 \mathrm{~cm}^{-1}$ is related to the bending vibration of $\mathrm{Si}-\mathrm{OH}$ group (silanol). Moreover, the presence of a broad band in 13450 and $1650 \mathrm{~cm}^{-1}$ is corresponded to the stretching and bending vibrations of the $\mathrm{H}-\mathrm{O}-\mathrm{H}$ bond of water molecules and surface hydroxides, respectively. Also, the band in near $1453 \mathrm{~cm}^{-1}$ represents the bending vibration of Si-O tetrahedral $[11,12]$.

\section{Conclusions}

In this study, the effect of various parameters on the oxidation reaction of methanol to formaldehyde was investigated. Among the various prepared catalysts, the best results were obtained Mo-Fe co-precipitated $\gamma-\mathrm{Al}_{2} \mathrm{O}_{3}$ with $\mathrm{Mo} / \mathrm{Fe}=1.7$ molar ratio and 50 wt.\% of metallic phase. This catalyst can promote conversion and selectivity at $350{ }^{\circ} \mathrm{C}$ to $97 \%$ and 96 $\%$, respectively. From the data collected from the catalytic performance and characterization analyzes within this work it seems the most important aspect to formaldehyde production is the presence of surface $\mathrm{Fe}_{2}\left(\mathrm{MoO}_{4}\right)_{3}$ and the reason of catalyst deactivation is the degradation of $\mathrm{Fe}_{2}\left(\mathrm{MoO}_{4}\right)_{3}$ and its smaller particle size. The particle size for the co-precipitated and impregnated catalysts are $29 \mathrm{~nm}$ and $16 \mathrm{~nm}$, respectively. This suggests that by increasing the particle size, the catalyst activity has increased, which is likely to indicate that the reaction is a structure-sensitive reaction. These obtained results are very important for industrial aims.

\section{References}

[1] Yeo, B.R., Pudge, G.J., Bugler, K.G., Rushby, A.V., Kondrat, S., Bartley, J., Golunski, S., Taylor, S.H., Gibson, E., Wells, P.P., Brookes, C. (2016). The Surface of Iron Molybdate Catalysts Used for the Selective Oxidation of Methanol. Surface Science, 648: 163-169.

[2] Cao, E., Gavriilidis, A. (2005). Oxidative Dehydrogenation of Methanol in a Microstructured Reactor. Catalysis Today, 110: 154-163.
[3] Andersson, A., Hernelind, M., Augustsson, O. (2006). A Study of the Ageing and Deactivation Phenomena Occurring during Operation of an Iron Molybdate Catalyst in Formaldehyde Production. Catalysis Today, 112: 40-44.

[4] Soares, A.P.V., Portela, M.F., Kiennemann, A., Hilaire, L. (2003). Mechanism of Deactivation of Iron-Molybdate Catalysts Prepared by Coprecipitation and Sol-Gel Techniques in Methanol to Formaldehyde Oxidation. Chemical Engineering Science, 58: 1315-1322.

[5] Bowker, M., Holroyd, R., House, M., Bracey, R., Bamroongwongdee, C., Shannon, M., Carley, A. (2008). The Selective Oxidation of Methanol on Iron Molybdate Catalysts. Topics in Catalysis. 48: 158-165.

[6] Soares, A.P.V., Portela, M.F., Kiennemann, A. (2005). Methanol Selective Oxidation to Formaldehyde over Iron-Molybdate Catalysts. Catalysis Reviews, 47: 125-174.

[7] Shi, D., Liu, J., Ji, S. (2017). Preparation of $\mathrm{Au} / \mathrm{TiO}_{2}$ Catalyst and the Performance of Liquid Methanol Catalytic Oxidation to Formic Acid. Industrial \& Engineering Chemistry Research, 56: 11028-11033.

[8] Soares, A.V., Portela, M.F., Kiennemann, A., Hilaire, L., Millet, J.M.M. (2001). Iron Molybdate Catalysts for Methanol to Formaldehyde Oxidation: Effects of Mo Excess on Catalytic Behavior. Applied Catalysis A: General, 206: 221-229.

[9] Peyrovi, M.H., Parsafard, N., Mohammadian, Z. (2017). Benzene Selective Hydrogenation over Supported Ni (nano-) Particles Catalysts: Catalytic and Kinetics Studies. Chinese Journal of Chemical Engineering, 26: 521528.

[10] Parsafard, N., Peyrovi, M.H., Rashidzadeh, M. (2014). n-Heptane Isomerization on a New Kind of Micro/Mesoporous Catalyst: Pt Supported on HZSM-5/HMS. Microporous and Mesoporous Material, 200: 190-198.

[11] Li, X., Li, B., Xu, J., Wang, Q., Pang, X., Gao, X., Zhou, Z., Piao, J. (2010). Synthesis and Characterization of Ln-ZSM-5/MCM-41 (Ln= La, Ce) by using Kaolin as Raw Material. Applied Clay Science, 50: 81-86.

[12] He, C., Li, P., Cheng, J., Wang, H., Li, J., Li, Q., Hao, Z. (2010). Synthesis and Characterization of Pd/ZSM-5/MCM-48 Biporous Catalysts with Superior Activity for Benzene Oxidation. Applied Catalysis A: General, 382: 167-175. 